Dicle University Journal of Engineering (DUJE)

web: http://dergipark.gov.tr/dumf

Araștırma Makalesi / Research Article

\title{
Kromit Tesis Atıklarının Knelson ve Falcon Konsantratör ile Zenginleştirilmesi
}

\section{Enrichment of Chromite Processing Plant Tailing with Knelson and Falcon Concentrator}

\section{Selçuk Özgen ${ }^{1 *}$}

${ }^{1}$ Türkiye Kömür İșletmeleri Genel Müdürlüğü, Ankara, ozgens@tki.gov.tr; ozgen_s@ @hotmail.com

\begin{tabular}{|c|c|}
\hline \multicolumn{2}{|c|}{ MAKALE BİLGİLERİ } \\
\hline \multicolumn{2}{|c|}{ Makale geçmişi: } \\
\hline Geliş: & 5 Mayis 2020 \\
\hline Düzeltme: & 15 Temuuz 2020 \\
\hline Kabul: & 20 Temmuz 2020 \\
\hline
\end{tabular}

Kromit atığ 1 , Falcon konsantratör, Knelson konsantratör, Zenginleștirme

\begin{abstract}
ÖZET
Bu çalışmada, Fethiye/Üçköprü krom zenginleştirme tesis atıklarının zenginleştirilmesi falcon ve knelson konsantratör ile araștırılmıștır. Calıșmalar kapsamında Falcon ve Knelson Konsantratörlerin çalıșma parametrelerinden santrifüj kuvvet, yıkama suyu basıncı ve besleme hızının kromit zenginleştirmeye etkisi de araştırılmıştır. Deneysel çalışmalar sonucunda; \%13,27 $\mathrm{Cr}_{2} \mathrm{O}_{3}$ içeren kromit atı̆̆ından falcon konsantratör ile yapılan çalışmalarda en iyi sonuçlar $120 \mathrm{~kg} . \mathrm{m} / \mathrm{s}^{2} \mathrm{G}$ kuvveti, 3 psi yıkama suyu basıncı ve $1 \mathrm{lpm}$ besleme hızında $\% 67,25$ verim ve $\% 43,89 \mathrm{Cr}_{2} \mathrm{O}_{3}$ tenörle elde edilmiştir. Knelson konsantratör ile yapılan çalışmalarda ise en iy sonuçlar $100 \mathrm{~kg} . \mathrm{m} / \mathrm{s}^{2}$ G kuvveti, 4 psi yıkama suyu basınc1 ve $1 \mathrm{lpm}$ besleme hızında \%72,51 verim ve \%47,32 $\mathrm{Cr}_{2} \mathrm{O}_{3}$ tenörle elde edilmiştir. $\mathrm{Bu}$ sayede kromit atıkları oldukça yüksek bir verim ile satılabilir ürüne dönüştürülerek ekonomiye kazandırılmıştır.
\end{abstract}

Doi: $10.24012 /$ dumf. 801648

\begin{tabular}{|c|c|}
\hline ARTICLE INFO & ABSTRACT \\
\hline Article history: & This situation causes an increase in the ore preparation plant's wastes. In this study, enrichment of Fethiye / \\
\hline 5 May 2020 & $\begin{array}{l}\text { Uçköprü chromite processing plant tailing were investigated with falcon and knelson concentrator. In the studies, } \\
\text { the working parameters of Falcon and Knelson Concentrators were examined. These parameters are; centrifugal }\end{array}$ \\
\hline Revised: 15 July 2020 & force, wash water pressure and feed rate. In experimental studies, chromite waste containing $13.27 \% \mathrm{Cr}_{2} \mathrm{O}_{3}$ was \\
\hline Accepted: 20 July 2020 & used. The best results in the studies with the falcon concentrator were obtained at $120 \mathrm{~kg} \cdot \mathrm{m} / \mathrm{s}^{2} \mathrm{G}$ force, 3 psi wash \\
\hline Keywords: & $\begin{array}{l}\text { water pressure and } 1 \mathrm{lpm} \text { feed rate. In this experiment, } 67.25 \% \text { recovery and } 43.89 \% \mathrm{Cr}_{2} \mathrm{O}_{3} \text { tenor were obtained. } \\
\text { In studies with Knelson concentrator, the best results were obtained at } 100 \mathrm{~kg} \cdot \mathrm{m} / \mathrm{s}^{2} \mathrm{G} \text { force, } 4 \text { psi wash water }\end{array}$ \\
\hline $\begin{array}{l}\text { Chromite waste, Falcon } \\
\text { concentrator, Knelson } \\
\text { concentrator, Enrichment }\end{array}$ & $\begin{array}{l}\text { pressure and } 1 \mathrm{lpm} \text { feed rate. In this experiment, } 72.51 \% \text { recovery and } 47.32 \% \mathrm{Cr}_{2} \mathrm{O}_{3} \text { tenor were obtained. In this } \\
\text { way, chromite tailing are transformed into salable products with a high efficiency and brought into the economy. }\end{array}$ \\
\hline
\end{tabular}

\footnotetext{
* Sorumlu yazar / Correspondence

Selçuk ÖZGEN

$\bowtie$ ozgens@tki.gov.tr; ozgen_s@ @otmail.com
} 


\section{Giriș}

Endüstriden önemli bir yere sahip olan krom, bakır, alüminyum ve demirden sonra en çok kullanılan metaldir. Endüstrinin hızla gelişmesi bu metallerin kullanımı ve üretimini de hızla artırmış, buna paralel olarak cevher hazırlama atıklarının artmasına neden olmuştur. Bu durum hem çevresel problemleri beraberinde getirmiş hem de milli israfa yol açmıștır. Son yıllardaki teknolojik gelişmeler tesis atıklarının yeniden değerlendirilmesini gündeme getirmiştir. Kromit tesisi atıklarının da önemli miktarda krom içermesi dikkatleri üzerine çekmiştir.

Genel olarak kromit minerali fiziksel, fizikokimyasal ve/veya manyetik ayırıcılar ile zenginleştirilebilmesine rağmen kromit tesisi atığ1 yüksek oranda şlam yani çok ince boyutlu malzeme içermesinden

dolay 1 zenginleștirilmesinde çeşitli problemler çıkabilmektedir. Eskibalcı vd. [1] \%18,74 $\mathrm{Cr}_{2} \mathrm{O}_{3}$ tenörlü Kavak krom konsantratör tesisi atığını MGS ile zenginleştirilmesini araştırmışlardır. Zenginleştirme sonucunda \%64,42 verim ile $\% 47 \quad \mathrm{Cr}_{2} \mathrm{O}_{3}$ tenörlü konsantre üretmeyi başarmışlardır. Önal vd. [2] yaptıkları çalışmalarında Kavak ve Fethiye krom atıklarının yüksek alan şiddetli yaş manyetik ayırıcı ile zenginleştirilmesini araştırmışlardır. $\% 25,5 \mathrm{Cr}_{2} \mathrm{O}_{3}$ tenörlü Fethiye atı̆̆ından \%32,73 $\mathrm{Cr}_{2} \mathrm{O}_{3}$ tenörlü ön konsantreyi $\% 89,84$ verimle, $\% 16,37 \mathrm{Cr}_{2} \mathrm{O}_{3}$ tenörlü Fethiye atı̆̆ından \%21,27 $\mathrm{Cr}_{2} \mathrm{O}_{3}$ tenörlü ön konsantreyi $\% 78,50$ verimle elde etmişlerdir. Aydın [3] Kef konsantre tesisi atıklarının zenginleştirilmesini araştırmış ve ilk aşamada sallantılı masa ile $\% 34,08 \mathrm{Cr}_{2} \mathrm{O}_{3}$ tenörlü konsantre $\% 90$ verim ile, ikinci aşamada manyetik zenginleştirme ile \%45,21 $\quad \mathrm{Cr}_{2} \mathrm{O}_{3}$ tenörlü konsantre \%87,46 verim ile elde etmiștir. Özkan ve İpekoğlu [4], Üçköprü $\% 25,20 \mathrm{Cr}_{2} \mathrm{O}_{3}$ tenörlü konsantre tesis atıklarının geri kazanım konusunda araștırmıșlardır. -38 mikron tane boyutundaki tesis artıkları Multi gravite seperatör ile zenginleştirilmiş ve $\% 72,0$ verimle $\% 47,0 \mathrm{Cr}_{2} \mathrm{O}_{3}$ olan konsantre elde etmişlerdir.

Başka bir araştırmacı ise sallantılı masa ve MGS ile \%13,76 $\mathrm{Cr}_{2} \mathrm{O}_{3}$ tenörlü Kavak krom konsantre tesisi atığını zenginleştirmeye çalışmıştır [5]. 300 mikron tane boyutunda MGS ile yaptı̆̆ zenginleştirme sonucunda $\% 23,02 \mathrm{Cr}_{2} \mathrm{O}_{3}$ tenörlü konsantreyi \%68,35 verimle elde etmiştir. Farklı gravite zenginleștirme cihazları ile yapılan bir başka çalışmada ise düşük tenörlü kromit cevheri kullanılmıştır [6]. Çalışma kapsamında \%18,62 $\mathrm{Cr}_{2} \mathrm{O}_{3}$ tenörlü cevherin MGS, Falcon ve Knelson konsantratörle zenginleştirilebilmesi araştırılmıştır. En iyi sonuçlara falcon konsantratör ile ulaşılırken $\% 57,73 \mathrm{Cr}_{2} \mathrm{O}_{3}$ tenörlü konsantre $\% 63,95$ verimle elde edilmiştir.

Rath vd. [7], Odisha Mining Co.'a ait kromit zenginleştirme tesisi artıklarını SB-40 tipi Falcon gravimetrik ayırıcı ile zenginleştirilmesini araştırmışlardır. \%68,00'i -11 mikron olan $\% 20,23 \mathrm{Cr}_{2} \mathrm{O}_{3}$ içerikli artıktan \%68'in üzerinde bir verimle \%40'tan fazla $\mathrm{Cr}_{2} \mathrm{O}_{3}$ tenörlü bir konsantre elde etmişlerdir. Kıyak [8], $\% 5 \mathrm{Cr}_{2} \mathrm{O}_{3}$ içerikli Bursa Orhaneli Kromit zenginleştirme tesis atıklarının zenginleștirme olanaklarını Knelson santrifüj ayırıcısı ile araştırmıştır. $212+75,-75+38$ ve $-38 \mu \mathrm{m}$ tane boyutlarında ayrı ayrı besleme yaparak \%22,00 $\mathrm{Cr}_{2} \mathrm{O}_{3}$ tenörle ve $\% 75$ verimle kromit konsantresi elde etmiştir. Bozkurt [9], krom artıklarının geri kazanımında Knelson santrifüj ayırıcının etkilerini araştırmıştır. Yaptığı çalışmasında, \% $\% 2,28 \mathrm{Cr}_{2} \mathrm{O}_{3}$ tenörlü artıktan -212 mikron tane boyutunda, $\% 73,18$ verimle $\% 21,5 \quad \mathrm{Cr}_{2} \mathrm{O}_{3}$ tenörlü ön konsantre elde etmiștir.

Kromit atıklarının zenginleştirilmesiyle ilgili çalışmalarda özellikle son yıllarda gelişmiş gravite cihazlarının kullanımı artmış ve etkili olduğu görülmüştür. Ülkemizin önemli krom yataklarının bulunduğu Fethiye/Üçköprü bölgesinde yaklaşık 3 milyon ton $\% 9-20 \mathrm{Cr}_{2} \mathrm{O}_{3}$ tenörlü ve 1,2 milyon ton $\% 13-14 \mathrm{Cr}_{2} \mathrm{O}_{3}$ tenörlü krom zenginleștirme tesis atığ $\breve{1}_{1}$ bulunmaktadır [10]. Literatür taramalarında bu atıkların ekonomiye kazandırılması için çok çalışma bulunmamakta olup ileri gravite cihazlarından MGS (Multi gravite seperatör) ile yapılmış bir çalışmada \%48,18 $\quad \mathrm{Cr}_{2} \mathrm{O}_{3}$ tenörlü konsantre $\% 69,79$ tenör ile elde edilmiştir [10]. Bu çalışmada ise Fethiye/Üçköprü krom zenginleştirme tesis atığının zenginleştirilmesi falcon ve knelson zenginleştirme cihazları ile araștırılmıştır. $\mathrm{Bu}$ kapsamda her iki cihaz kullanılarak optimum şartlar belirlenmiş ve çalışma parametreleri ortaya konmuştur. 


\section{Materyal ve Metot}

\section{Materyal}

Çalışmada Üçköprü (Fethiye/Muğla) krom konsantre tesisinden temin edilen ince kromit atıkları kullanılmıştır. TSE Standartlarına uygun olarak atık havuzunun çeșitli yerlerinden temin edilen yaklaşık $500 \mathrm{~kg}$ kromit atığı homojen olarak karıştırılarak 0,5 mm'den elenmiştir. Çalışmalarda $0,5 \mathrm{~mm}$ altı tane boyutundaki kromit atıkları kullanılmış olup bu atıkların boyut dağılımları ve $\% \mathrm{Cr}_{2} \mathrm{O}_{3}$ içeriği Çizelge 1 'de verilmiştir. Çizelgeden de görüldüğü gibi atığın büyük kısmı 38 mikron altında olup, ortalama $\% 13,27 \quad \mathrm{Cr}_{2} \mathrm{O}_{3}$ içermektedir. $0,5 \mathrm{~mm}$ üstü malzemeler ise alternatif zenginleştirme yöntemlerinde değerlendirmek üzere ayrılmıştır.

Çizelge 1. Tane boyutuna bağlı $\mathrm{Cr}_{2} \mathrm{O}_{3}$ dağılımı.

\begin{tabular}{lll}
\hline $\begin{array}{l}\text { Tane Boyutu } \\
(\boldsymbol{\mu m})\end{array}$ & $\begin{array}{l}\text { Miktar } \\
(\boldsymbol{\%})\end{array}$ & $\begin{array}{l}\mathrm{Cr}_{2} \mathrm{O}_{3} \\
(\boldsymbol{\%})\end{array}$ \\
\hline$-500+300$ & 11,96 & 10,28 \\
$-300+106$ & 15,65 & 11,12 \\
$-106+38$ & 23,14 & 12,14 \\
-38 & 49,25 & 15,21 \\
Toplam & 100 & 13,27 \\
\hline
\end{tabular}

\section{Metot}

\section{Kromit atı̆̆ının hazırlanması}

Üçköprü kromit konsantre tesisinden temin edilen kromit atıklarının tamamı 0,5 mm'den elenerek kurutulmuştur. Falcon ve Knelson konsantratör zenginleştirme işlemlerinde $-0,5$ mm boyutundaki kısım kullanılmış ve herhangi bir kırma/öğütme yapılmamıştır. Çalışmalarda kullanılan akım şeması Șekil 1'de verilmiștir.

\section{Falcon ve Knelson Konsantratörler}

Son yıllarda gravite metotlarındaki gelişmelere bağlı olarak üretilen yüksek santrifüj etkili cihazlardan olan iki farklı zenginleştirme ekipmanı falcon ve knelson konsantratörler kullanılmıştır (Şekil 2).

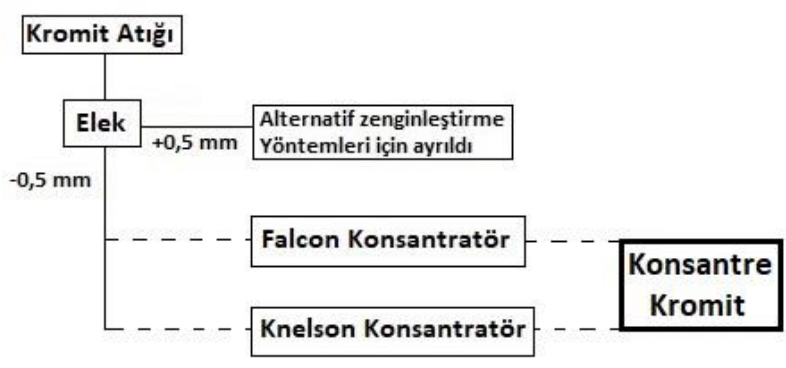

Şekil 1. Deneysel akım şemast.

Falcon Konsantratör, Vancouver'da FalconConcentrator Company tarafindan üretilmiştir. Falcon konsantratörü, yüksek merkezkaç kuvveti oluşturabilen gravite separatördür. Ürün beslemesi, hızla dönen iç koniğe yapılır ve bu malzeme pervane aracılığıyla ivmelendirilerek koniğin çevresi boyunca hareket eder. Hareket eden koniğin üst kısmı bir alıkonma zonu olarak işlem görürken dip kısmı hareket zonu sağlamak için belli bir açıda eğimlidir. Daha güçlü merkezkaç kuvvetler hareket zonundaki tanenin tabakalaşmasını ve çökelmesini engelleyecek şekilde etki yapar. Hafif taneler düşük özgül ağırlıkları ya da küçük boyutlarından dolayı koniğin dişına doğru hareket eder. Ağır taneler ise konsantrasyon (alıkonma) zonunda kalarak yıkama suyuyla birlikte yıkanarak temiz konsantre üretilir [11]. Hem laboratuvar ölçekli hem de ticari ölçekli çalışmalarda demir, kalay, titanyum ve altın cevherleri gibi yoğunluğu yüksek minerallerin zenginleştirilmesinde kullanılır. Üç çeşit falcon konsantratör mevcuttur: SB-40 (SemiContinuous), C (Continuous) ve UF (kesikli ve çok ince taneli cevherler). Bu cihazlar $300 \mathrm{G}$ kadar santrifüj kuvvet üreterek 10 mikrona kadar küçük taneciklerin zenginleştirilmesini sağlar. $\mathrm{Bu}$ çalışmada SB-40 yarı kesikli modeli kullanılmıştır. Falcon SB'ye çalışmalar sırasında devamlı olarak besleme yapılabildiği fakat yalnızca periodik olarak hazne yıkama esnasında konsantre üretilebildiği için yarı kesikli cihazlar denir. $\mathrm{Bu}$ konsantratörler yerçekiminin 50 katından 200 katına kadar santrifüj kuvvet üretebilmektedir.

Knelson Konsantratör, Byron Knelson tarafından 1988 yılında Kanada'da patenti alınmıştır. Dünyada damar tipi ve alüvyon altın üretiminde kullanım alanına sahip yüksek hızlı santrifüj seperatördür [12]. Knelson 
konsantratör, dönme işlemini gerçekleştiren üniteyle birlikte, yüksek hızda dönen bir yataktan oluşur. Üst kısımdan beslenen malzeme içerisindeki ağır taneler santrifüj kuvvetinin etkisiyle konsantre olarak yatağın oluklarına takılır. Besleme içerisindeki gang mineralleri ise atık olarak üst akışıyla birlikte atılır. Malzeme beslemesi, knelson konsantratörün haznesi içine düşey bir tüp vasıtasıyla yapılmaktadır. Yapılan besleme \%0-70 katı yoğunluğunda olabilir. Haznenin alt kısmında beslemeyi dağıtacak olan bir pervane mevcuttur [13]. İlk üretilen knelson konsantratörler yerçekimi ivmesinin ortalama 60 katı kadar bir santrifüj kuvvet oluşturabilmektedir [14]. Sonraki modeller yerçekimi kuvvetinin 200 katına kadar çıkabilmektedir. Falcon konsantratörde olduğu gibi sürekli (Continuous) ve yerı kesikli (SemiContinuous) modelleri mevcuttur. Bu çalışmada da $65 \mathrm{ml}$ sepet kapasitesi bulunan KC-MD3 yarı kesikli modeli kullanılmıştır.

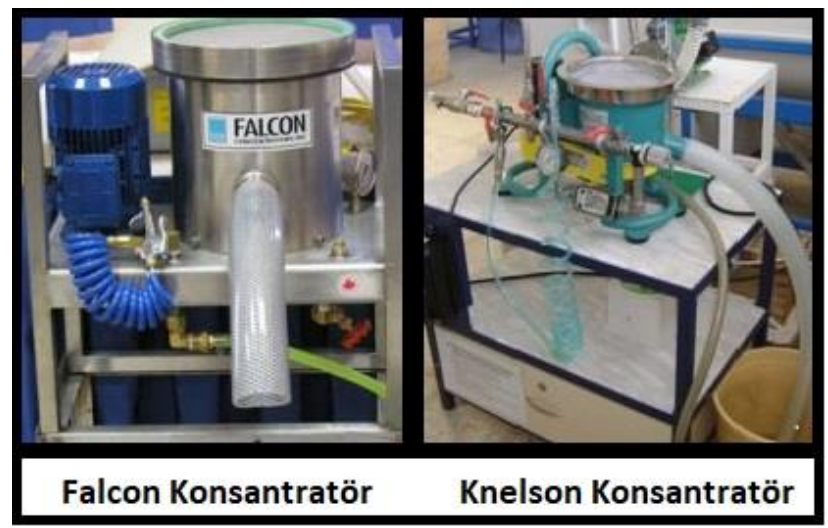

Şekil 2. Deneylerde kullanılan falcon ve knelson konsantratörler.

\section{Kromit Zenginleştirme}

Zenginleştirme deneyleri öncesi $-0,5 \mathrm{~mm}$ elenen kromit atığı 20 lt tank içerisine \%20 katı oranı olacak şekilde hazırlanmıştır. Bütün deneyler sabit katı oranında yapılmıştır. Falcon ve knelson konsantratör deneylerinde aynı değişkenler kullanılmıştır. Bunlar; G kuvveti $(\mathrm{G})$, yıkama suyu basinc1 (P) ve besleme hizidir (H). Deneylerde kullanılan bu değişkenlere ait seviyeler Çizelge 2'de verilmiştir.

Falcon ve Knelson konsantratörleri, önceden belirlenmiş G kuvveti ve yıkama suyu basıncında dengeye ulaşana kadar besleme yapılmadan çalıştırılmıştır. Sistem dengeye ulaştıktan sonra, önceden hazırlanan \% 20 katı oranındaki pülp belirlenen besleme hizında konsantratörlere beslenmiștir. Bütün besleme tamamlandıktan sonra y1kama suyu 15 saniye daha devam etmiştir. Parametreler ayrı ayrı optimize edilmiştir. Bir parametre optimize edilirken diğer parametreler sabit tutulmuştur. Bu şekilde bir seri deney yapılmış ve deney sonunda konsantre ve atık ayrı ayrı alınarak kromit analizleri yapılmıştır.

Çizelge 2. Falcon ve knelson konsantratör deney parametreleri.

\begin{tabular}{lcc}
\hline Parametre & Birim & Seviyeler \\
\hline G Kuvveti (G) & kg.m/s & $60-80-100-120-140$ \\
\hline Y1kama Suyu & Psi & $1-2-3-4-5$ \\
Basinc1 (P) & & \\
\hline Besleme Hizi (H) & lpm & $1-2-3-4-5$ \\
\hline
\end{tabular}

\section{Sonuçlar ve Tartışma}

\section{Kromit zenginleştirmeye G kuvvetinin etkisi}

Falcon ve Knelson konsantratörlerinin en önemli özelliklerinden biri olan merkezkaç kuvveti, ince ve ultra ince tanelerin yoğunluk farkından yararlanarak süspansiyondaki çökelme hızlarını artırmasıdır. Bu şekilde, yan minerallerden daha yüksek özgül ağırlığa sahip kromit minerallerinin zenginleştirilmesi sağlanır. G kuvvetinin etkisini belirlemek için yıkama suyu basıncı 1 psi'de ve besleme hız $1 \mathrm{lpm}$ sabit tutularak bir seri deneyler yapılmıştır. $\mathrm{Bu}$ deneylerde $G$ kuvveti 60-80-100-120-140 $\mathrm{kg} . \mathrm{m} / \mathrm{s}^{2}$ olarak değiştirilmiştir. Farklı G kuvveti ile elde edilen sonuçlar, Şekil 3'de verilmektedir. Şekil 3'den görülebileceği gibi, falcon konsantratör deneylerinde en yüksek tenör 120 $\mathrm{kg} . \mathrm{m} / \mathrm{s}^{2}$, de $\% 42,15 \mathrm{Cr}_{2} \mathrm{O}_{3}$ olarak elde edilirken, knelson konsantratörde en yüksek tenör 100 kg.m $/ \mathrm{s}^{2}$, de $\% 43,95 \mathrm{Cr}_{2} \mathrm{O}_{3}$ olarak elde edilmiştir. Ayn1 deneylerde ${ }_{0} \mathrm{Cr}_{2} \mathrm{O}_{3}$ verimi falcon konsantratör için \%72,12, knelson konsantratör için \% 78,41 elde edilmiştir. En yüksek tenörlerin elde edildiği deneyler optimum nokta olarak kabul edilmiş ve sonraki deneylerde bu G kuvveti kullanılmıştır. Daha yüksek $G$ kuvvetlerinde tenör ve verimde düşüşler gözlenmiştir. Bunun nedeninin $G$ kuvveti arttıkça bağlı tanelerin de toplama haznesinde kalmaya başlaması ve bazı 
tanelerin ise oluşan yatakla birlikte dişarıya taşınması olduğu düşünülmektedir. Çalışmada kullanılan model yarı kesikli olduğu için haznede dolmalara rastlamak mümkündür. Sürekli sistemde yapılan çalışmalarda buna benzer verim ve tenör düşüşleri görülmeyebilir.

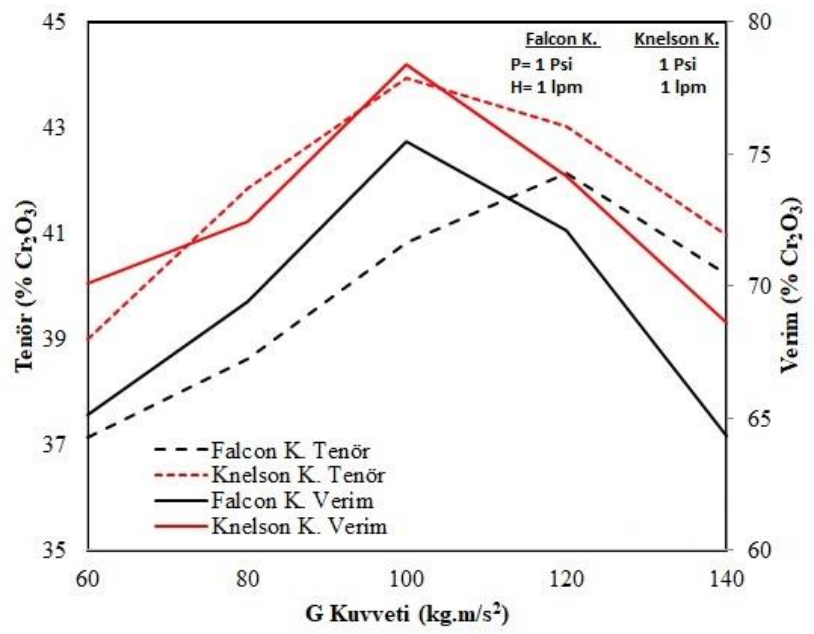

Şekil 3. G kuvvetinin kromit zenginleştirmeye etkisi.

Kromit zenginleştirmeye yıkama suyu basıncının etkisi

Falcon ve Knelson konsantratörlerde yıkama suyu basıncının iki önemli etkisi vardır. Birincisi, aşağıdan yukarıya doğru akışkan bir yatak oluşturmaktır. Bu yatak sayesinde hafif özgül ağırlığa sahip mineraller taşarak dışarıya alınır. İkincisi ise hafif yoğunluklu minerallerin daha ağır yoğunluklu minerallerin arasında sıkışması önlenir. Böylece daha temiz konsantreler elde edilebilir. Yıkama suyu basıncinın etkisini belirlemek için G kuvveti ve besleme hızı sabit tutularak bir seri deneyler yapılmıştır. Bu deneylerde yıkama suyu basincı 1-2-3-4-5 psi olarak değiştirilmiştir. Besleme hızı 1 lpm olarak sabit tutulurken, G kuvvetleri bir önceki deneyde optimum sonuçların elde edildiği falcon konsantratör için $120 \mathrm{~kg} \cdot \mathrm{m} / \mathrm{s}^{2}$, knelson konsantratör için $100 \quad \mathrm{~kg} \cdot \mathrm{m} / \mathrm{s}^{2}$ olarak belirlenmiştir. Farklı yıkama suyu basıncında elde edilen sonuçlar, Şekil 4'de verilmektedir. Şekil 4'den görülebileceği gibi, falcon konsantratör deneylerinde en yüksek tenör 5 psi'da \%46,02 $\quad \mathrm{Cr}_{2} \mathrm{O}_{3}$ olarak elde edilirken, knelson konsantratörde en yüksek tenör 5 psi'da $\% 47,56 \mathrm{Cr}_{2} \mathrm{O}_{3}$ olarak elde edilmiştir. Kromit zenginleştirme veriminde ise tenöre göre ters korelasyon gözlenmiştir. Maksimum tenörün elde edildiği 5 psi yıkama suyu basıncinda yapılan deneylerde en düşük $\% \mathrm{Cr}_{2} \mathrm{O}_{3}$ verimleri elde edilmiştir. $\mathrm{Bu}$ deneylerde falcon konsantratör için \%58,41, knelson konsantratör için \%60,35 $\mathrm{Cr}_{2} \mathrm{O}_{3}$ verimi elde edilmiştir. Hem verim hem de tenör değerleri dikkate alındığında falcon konsantratör için 3 psi yıkama basıncında, knelson konsantratör için 4 psi yıkama suyu basincinda yapılan deneyler optimum olarak kabul edilmiş ve sonraki aşamaya geçilmiştir. $\mathrm{Bu}$ deneylerde falcon konsantratörde $\% 43,89 \mathrm{Cr}_{2} \mathrm{O}_{3}$ tenörü $\% 67,25$ verim ile knelson konsantratörde $\% 47,32 \quad \mathrm{Cr}_{2} \mathrm{O}_{3}$ tenörü \%72,51 verimle elde edilmiştir. Yıkama suyu basıncı arttıkça tenörün artması ve verimin düşmesinin nedeni hafif minerallerin atık haznesine taşınması için oluşan akışkan yatağın biraz daha ağır taneleri de (bağlı taneleri) atık haznesine taşımaya başlamasıdır. Bu yüzden konsantre kısmında daha az bağlı tane kaldığı için tenör yükselmekte ancak bağlı tanelerde kromit minerali bulunduğu için verim düşmektedir. $\mathrm{Bu}$ yüzden yıkama suyu basınc1 kritik bir öneme sahip parametre olmaktadır.

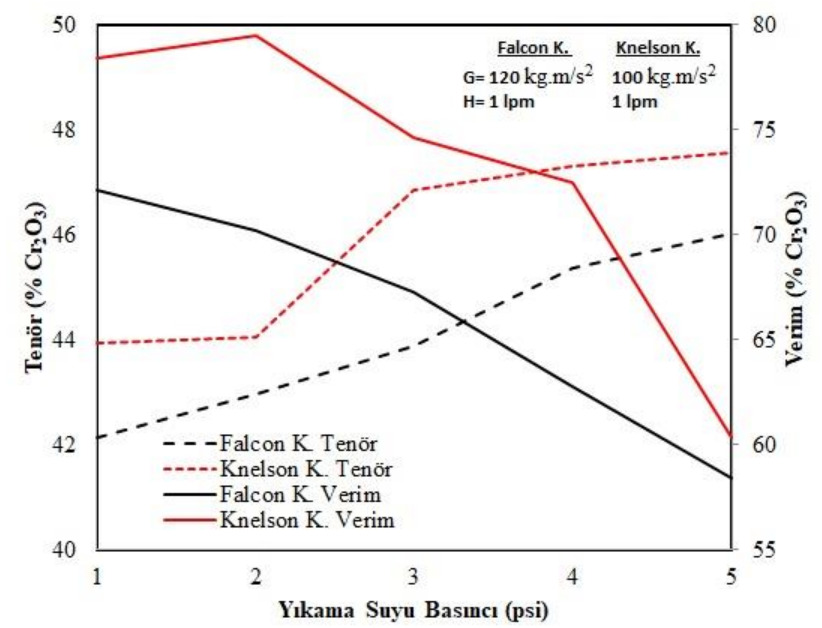

Şekil 4. Yıkama suyu basıncının kromit zenginleştirmeye etkisi.

\section{Kromit zenginleştirmeye besleme hızının etkisi}

Falcon ve knelson konsantratörlerde zenginleştirmeyi etkileyecek bir diğer parametre ise besleme hizıdir. Besleme hızı konsantratörlere verilen birim zamandaki kat1 miktarı ile ilişkilidir. Katı oranı da değiştirilerek te benzer sonuçlar elde edileceği için bütün deneylerde katı oranı sabit tutulmuştur. Besleme hızı etkisini belirlemek için G kuvveti ve yıkama 
suyu basıncı bir önceki deneylerde elde edilen optimum sonuçlarda sabit tutularak bir seri deneyler yapılmıştır. Bu deneylerde besleme hızı 1-2-3-4-5 lpm olarak değiştirilmiştir. Diğer parametrelerin optimum sonuçları ise falcon konsantratör için G kuvveti $120 \mathrm{~kg} \cdot \mathrm{m} / \mathrm{s}^{2}$ ve yıkama suyu basinc 3 psi, knelson konsantratör için G kuvveti $100 \mathrm{~kg} . \mathrm{m} / \mathrm{s}^{2}$ ve yıkama suyu basınc1 4 psi'dır. Farklı besleme hızlarında elde edilen sonuçlar, Şekil 5'de verilmektedir. Şekil 5 'den görülebileceği gibi, diğer iki parametreden farklı olarak verim ve tenörün benzer şekilde besleme hızı arttıkça bunların düştüğü görülmüştür. Bunun nedeninin besleme hızı arttıkça konsantratörler içerisinde birim sürede bulunan katı miktarının artması taneciklerin seçici bir şekilde ayrılmasını zorlaştırdığı ve bu yüzden tenör ve verimde düşüşlerin gözlenmesine neden olduğu düşünülmektedir. En yüksek verim ve tenör $1 \mathrm{lpm}$ besleme hızında elde edilmiștir. Bu şartlarda falcon konsantratör ile \%72,51 verimle \%47,32 $\mathrm{Cr}_{2} \mathrm{O}_{3}$ tenörlü konsantre elde edilmiştir.

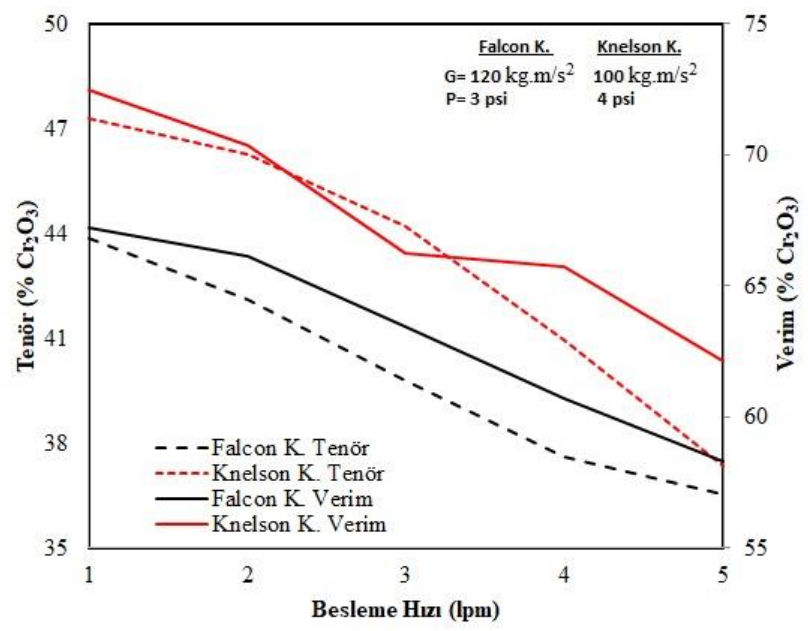

Şekil 5. Besleme hızının kromit zenginleştirmeye etkisi.

\section{Sonuçlar}

Fethiye/Üçköprü krom zenginleştirme tesis atıklarının falcon ve knelson konsantratör ile zenginleştirildiği bu çalışmada, cihazların parametrelerinin krom zenginleştirmeye etkileri de belirlenmiştir. Yapılan deneysel çalışmaların sonucunda \%13,27 $\mathrm{Cr}_{2} \mathrm{O}_{3}$ içeren kromit atığ1 falcon konsantratör kullanılarak $\% 43,89 \mathrm{Cr}_{2} \mathrm{O}_{3}$ tenörlü konsantre ürün $\% 67,25$ verim ile elde ediliken, knelson konsantratörde $\% 47,32 \mathrm{Cr}_{2} \mathrm{O}_{3}$ tenörlü ürün $\% 72,51$ verimle elde edilmiştir.

Endüstrinin hızla gelişmesi kromit ihtiyacını artırmakta ve kromit atıklarının kullanımını güncel tutmaktadır. Bu çalışma sayesine hem çevresel bir probleme neden olan hem de atıl olarak bekleyen düşük tenörlü kromit atıkları basit ama gelişmiş gravite cihazlar ile yüksek sayılabilecek bir verimle tek aşamalı olarak zenginleştirilerek satılabilir tenör olan $\% 42$ $\mathrm{Cr}_{2} \mathrm{O}_{3}$ 'ün üzerine çıkılarak çalışma hedefine ulaşılmıştır. $\mathrm{Bu}$ sayede çalışma içerisinde sunulan deneysel akım şemasında olduğu gibi 0,5 $\mathrm{mm}$ elekten elenerek $-0,5 \mathrm{~mm}$ atı bu yöntemler ile kazanilabilecektir. Ayrıca $+0,5 \mathrm{~mm}$ boyutundaki kromit atığ1 ise ince boyuta göre daha kolay yöntemler (sallantılı masa gibi) ile değerlendirilebilecektir.

Cihazların çalıșma parametrelerini ayrı ayrı değerlendirmek için yapılan seri deneyler sonucunda $\mathrm{G}$ kuvvetinin etkisinin benzer olduğu ancak optimum sonuçlara falcon konsantratörde 120 G'de, knelson konsantratörde 100 G'de ulaşılmıştır. Ayrıca yıkama suyu basıncının artmasiyla konsantre tenörünün $\operatorname{artt1ğg~ve~}$ veriminin düştüğü belirlenmiştir. Bu kromit atığ1 için tenör ve verimler dikkate alınarak optimum şartlar belirlenmiş olup, değișen çalışma koşullarına göre bu parametrenin istenilen konsantre kalitesine göre ayarlanabileceği ortaya konmuştur. Bunun dışında besleme hızının üretilen konsantre tenörü ve verimi üzerinde negatif bir etkisi olduğu belirlenmiştir. $\mathrm{Bu}$ yüzden mümkün olan en düşük besleme hızlarında çalışmanın avantajlı olduğu görülmüştür.

Sonuç olarak atıl durumda bekleyen binlerce ton krom atığ1 basit zenginleștirme prosesleri ile satılabilir tenörün çok üstünde bir tenöre ulaştırılarak ekonomiye kazandırılması ve bu sayede ciddi miktarda gelir elde edilmesinin mümkün olduğu kanıtlanmıştır.

\section{Kaynaklar}

[1] Eskibalc1, F., Çinku, K., Kurşun, İ., Özkan, Ş.Ü., (2002). "Kavak Yöresi Kromit Atıklarının MGS cihazı Kullanılarak Zenginleştirilmesi”, İstanbul Üniversitesi Mühendislik Fakültesi Yerbilimleri Dergisi, 15(2), 55-62. 
[2] Önal, G., Gürkan, V., Acarkan, N., (2005). "Krom Zenginleştirme Tesisleri Artıklarının Yüksek Alan Şiddetli Yaş Manyetik Ayırma ile Değerlendirilmesi”, İstanbul Teknik Üniversitesi, İstanbul.

[3] Aydın, M.E., (2001). "Etibank Guleman Kef konsantratör tesisi kromit artıklarının değerlendirilmesi”, Yüksek Lisans Tezi, Dicle Üniversitesi Fen Bilimleri Enstitüsü, Diyarbakır. 38.

[4] Özkan, Ş.G., İpekoğlu, B., (2001). "Concentration studies on chromite taillings by multi gravity seperator", 17th International Mining Congress and Exhibition IMCET, Turkey: 765-768.

[5] Çetinkaya, F., (2004). "Kavak-Krom Artıklarının Zenginleştiribilirliğinin Araştırılması", Yüksek Lisans Tezi, Osmangazi Üniversitesi Fen Bilimleri Enstitüsü, Eskişehir.

[6] Er, B., (2011). "Multi gravite cihazlarının krom cevheri zenginleştirmesindeki etkilerinin araştırılması", Yüksek Lisans Tezi, Dokuz Eylül Üniversitesi Fen Bilimleri Enstitüsü, İzmir.

[7] Rath, R. K., Dey, B., Mohanta, M. K., Prusty, L. K., And Singh, R., (2017). "Recovery of chromite values from tailings of COB plant using enhanced gravity concentrator", International Conference on Mineral Processing Technology, Indian Institute of Mineral Engineers, Chennai, 644-649.
[8] Kıyak, T., (2013). “Orhaneli krom zenginleştirme tesis atıklarının Knelson konsantratörü kullanılarak zenginleştirilmesi”, Yüksek Lisans tezi, Dumlupınar Üniversitesi Fen Bilimleri Enstitüsü, Kütahya.

[9] Bozkurt, B. (2017). "Kromun Zenginleştirme Tesis Atıklarından Geri Kazanımında Knelson Gravite Konsantratörünün Etkisi”, Yüksek Lisans Tezi, Afyon Kocatepe Üniversitesi, Afyon.

[10] Özgen, S. (2012). "Clean Chromite Production from Fine Chromite Tailings by Combination of Multi Gravity Separator and Hydrocyclone", Separation Science and Technology, 47 (2012) 1948-1956.

[11] Celep, O. (2005). "Mastra ve Kaletaş (Gümüşhane) cevherlerinden altın kazanımı”, Yüksek Lisans Tezi, Karadeniz Teknik Üniversitesi, Trabzon.

[12] Celep, O., Alp, İ., Deveci, H., Vicıl, M. ve Yılmaz, T. (2006). "Knelson santrifüj gravite ayırıcısıyla Mastra (Gümüşhane) cevherinden altın kazanımı”, Yerbilimleri Dergisi, 19 (2), 175-182.

[13] Knelson, B. ve Jones, R., (1993). “A New Generation of Knelson Concetrators a Totally Secure System Goes on Line", Mineral Engineering, 7,201-207.

[14] Huang, L., (1996). "Upgrading of Gold Gravity Concentrates: A Study of the Knelson Concentrator", Doktora Tezi, Department of Mining and Metallurgical Engineering, McGill University, Montreal. 